\title{
Modos sensiveis de criação infantil: uma inflexão no processo de medicalização dos cuidados com crianças
}

\section{Sensitive modes of child rearing: an inflection in the process of medicalization of childcare}

\author{
Alessandra Hernandez ${ }^{a}$ \\ (D) https://orcid.org/0000-0001-9710-0216 \\ E-mail: riverohernandezœhotmail.com \\ Ceres Víctora ${ }^{b}$ \\ (D) https://orcid.org/0000-0001-9363-3883 \\ E-mail: ceresvictoraœgmail.com \\ aPesquisadora autônoma. Porto Alegre, RS, Brasil. \\ bUniversidade Federal do Rio Grande do Sul. Departamento de \\ Antropologia. Programa de Pós-Graduação em Antropologia \\ Social. Porto Alegre, RS, Brasil.
}

\section{Resumo}

O objetivo deste artigo é analisar os discursos e as práticas relacionados aos modos sensíveis de criação infantil e sua articulação com a medicalização dos cuidados com crianças, entendida como um processo pelo qual problemas não médicos passam a ser definidos e tratados como problemas médicos. Esse conjunto variado de práticas de cuidado emerge da crítica à medicalização da infância, sobretudo, aos preceitos cientificistas que regem o exercício de uma "maternidade científica", visto por seus praticantes como um retorno ao "natural" e "tradicional". Este trabalho apresenta uma reflexão baseada em pesquisa etnográfica desenvolvida em Porto Alegre/RS, Brasil. A partir das principais controvérsias estabelecidas em torno do choro infantil, argumenta-se que os modos sensíveis de criação infantil, apesar do que as críticas formuladas por seus praticantes levam a pensar, estão mais próximos de certos valores ocidentais modernos e tributários do Romantismo. Concluise que esse estilo de criação infantil, mais do que um retorno ao "natural" ou uma desmedicalização, constitui uma inflexão contemporânea no processo de medicalização dos cuidados com crianças.

Palavras-chave: Corpo; Emoções; Cuidado da Criança; Individualismo; Medicalização.

\section{Correspondência}


In this paper we analyze the discourses and practices related to sensitive modes of child rearing and their connection to the medicalization of childcare, understood as a process by which non-medical problems have come to be defined and treated as medical problems. "Sensitive modes of child rearing" refer to a heterogeneous group of care practices that has emerged from criticism of the process of medicalization of childhood, particularly of the scientific precepts that govern the exercise of "scientific maternity", and that is seen by its practitioners as a return to the "natural" and "traditional". Our study is a reflection based on ethnographic research carried out in Porto Alegre, Rio Grande do Sul, Brazil. We discuss the main controversies surrounding the two models, such as that concerning the baby's crying, and argue that the sensitive modes - contrary to what we are led to believe by its practitioners - are closer to certain modern Western values and tributaries of those values originating in Romanticism. In conclusion, we propose that sensitive modes of child rearing, rather than representing a return to the "natural" or a de-medicalization, constitutes a contemporary inflection in the process of the medicalization of childcare.

Keywords: Body; Emotions; Child Care; Individuation; Medicalization.
Este artigo tem como foco um conjunto variado de práticas de criação infantil que emerge da crítica a certos elementos constitutivos da vida contemporânea, em especial, ao processo de medicalização da infância. A partir da revisão bibliográfica sobre o tema da medicalização dos cuidados com crianças, colocada em diálogo com dados de uma pesquisa etnográfica sobre modos sensíveis de criação infantil, pretendemos discutir a emergência de novas sensibilidades e suas relações com o referencial médico.

Denominamos de modos sensíveis de criação infantil a toda essa diversidade de práticas que, como característica em comum, colocam em evidência os sentidos do corpo, e exaltam as experiências, as percepções, os afetos, as emoções, a intuição e a empatia. Entre essas práticas estão, por exemplo, a amamentação em livre demanda (sempre que a criança quiser, sem horários fixos) e, ao longo dos primeiros anos de vida da criança, o baby-led weaning (BLW), ${ }^{1}$ o coleito, ${ }^{2}$ o ato de carregar o bebê em um pano (sling) amarrado junto ao corpo do cuidador; o uso de fraldas de pano; o banho de balde; a massagem indiana shantala; a disciplina positiva; ${ }^{3}$ e propostas educativas pautadas na experimentação como forma de aprendizagem. Em cada uma dessas ações, emergem valores importantes que estão em jogo nos modos sensíveis de criação infantil. Assim, por exemplo, na amamentação, no uso do sling, na shantala e no coleito se produz uma intensa vinculação corporal; já na amamentação em livre demanda (diferentemente da amamentação com horários fixos), no BLW e na disciplina positiva se estabelece um modo de se relacionar com a criança (expressa em termos como "acolhimento das necessidades", "empatia" e "respeito pela criança”) que enaltece a agência infantil; ainda, na amamentação, no uso do sling e no coleito há

\footnotetext{
1 Um modo de introduzir a alimentação sólida em porções que permitem aos bebês pegarem os alimentos com suas mãos, comendo assim o que, o quanto e na velocidade que quiserem. Para maior detalhamento, ver Rapley e Murkett (2012).

2 Pode ser realizado de diferentes modos. Uma dessas maneiras é propriamente o compartilhamento de uma mesma cama. Outra forma é unir o berço ou a cama da criança à cama dos pais. Ainda, quando o ambiente de dormir é o mesmo, mas as camas estão separadas, pode-se falar em coabitação.

3 Em oposição a uma disciplina "negativa” em que a aprendizagem se daria por meio de proibições, castigos e punições.
} 
a valorização do que é considerado um retorno ao "natural" e ao "tradicional".

Além disso, algumas dessas práticas constituem um estilo de criação infantil que começou a despontar a partir da década de 1990 e vem sendo denominado de diferentes formas, entre elas: maternagem/paternagem/maternidade/ paternidade consciente, ativa ou, ainda, criação com apego. $\mathrm{O}$ termo apego presente nessa última designação faz referência à teoria do apego, proposta pelo médico psiquiatra e psicanalista britânico John Bowlby (1907-1990). Tal teoria chama a atenção para a importância dos vínculos afetivos nos primeiros anos de vida como condição para o desenvolvimento normal dos seres humanos.

Tais práticas de cuidado surgem em meio a um intenso processo de medicalização do cuidado cotidiano de crianças. Neste trabalho, a medicalização é entendida, como referido por Peter Conrad (1992), como um processo pelo qual problemas não médicos passam a ser definidos e tratados como problemas médicos, consiste em um fenômeno amplo e sutil que não se limita à incorporação de um problema ou de um comportamento ao campo de conhecimentos e práticas da medicina. Para o autor, embora essa dimensão possa estar presente (como bem salientado nos textos utilizados para situar historicamente a medicalização da criação infantil), esse processo opera também em um plano conceitual, quando uma linguagem médica é usada para descrever determinado problema, ou um modelo médico é adotado para entender um problema. Assim, a medicalização, enquanto fenômeno de definição de um problema em termos médicos, em determinados casos pode incluir marginalmente, ou até mesmo não incluir, profissionais médicos (como ocorre, por vezes, no campo de práticas descritas neste trabalho). Conrad (1992) afirma ainda que a medicalização é uma via de mão dupla, abrangendo também a desmedicalização, ou seja, quando um problema deixa de ser visto em termos médicos.

De acordo com Jacques Donzelot (1980), foi a partir do século XVIII que o Estado francês passou a intervir de distintas formas sobre as famílias para a sobrevivência das crianças. Uma dessas maneiras de intervenção voltou-se para o fortalecimento da elite francesa e operou-se por meio de uma aliança com a medicina, que até aquele momento não tinha manifestado interesse nas crianças. O costume de delegar o cuidado das crianças de famílias aos serviçais passou a ser fortemente criticado, enquanto as amas de leite passaram a ser apontadas como responsáveis pelos altos índices de mortalidade infantil. Uma abundante literatura médica sobre a criação e a educação de crianças começou a difundir a medicina doméstica, ou seja, conhecimentos e técnicas para que as mulheres burguesas assumissem o papel de cuidar e educar seus filhos.

No Brasil, segundo Jurandir Freire Costa (2004), a medicalização dos cuidados com crianças se deu durante o século XIX, quando se estabeleceu uma aliança entre Estado e médicos, a qual se valeu dos preceitos da higiene para conferir às famílias da elite uma educação física, moral, intelectual e sexual dirigida especialmente às crianças, para dessa forma converter essas famílias ao Estado. A ideia de que a capacidade de gestar, parir e amamentar fazia parte da natureza feminina passou a fundamentar o discurso médico a fim de legitimar o cuidado e a criação infantil como funções da mulher. Contudo, como refere Martha Freire $(2006,2008)$, tal discurso sofreu uma inflexão a partir da década de 1920 no Brasil, à semelhança do que ocorreria no contexto europeu e norte-americano: sem abandonar totalmente o discurso do instinto maternal, passou a se amparar no emprego de conhecimentos técnicos e científicos para a prática de criação infantil. Associando-se ao projeto modernizador republicano, os preceitos da "maternidade científica” (Apple, 1987) se fundamentavam na crítica às formas tradicionais de criação dos filhos, tidas como atrasadas, e buscavam reconfigurá-las com base em conceitos e modelos médicos vigentes na época, no campo da puericultura.

Matérias escritas, sobretudo por médicos, em revistas destinadas ao público feminino que circularam nas cidades do Rio de Janeiro e São Paulo, na década de 1920, difundiam os preceitos da "maternidade científica". Uma atenção especial era dada à alimentação infantil que se 
converteu em uma atividade científica, com base na higiene e na nutrição, atentando para o valor calórico dos alimentos, entre outros aspectos nutricionais. Orientava-se a prática disciplinada da amamentação (com número e intervalos das mamadas regrados e a proibição de mamadas noturnas), bem como a dosagem e a preparação de fórmulas para alimentação das crianças e mingaus, seguindo a prescrição médica. Berços e carrinhos se transformaram em objetos de higienização dos afetos, um recurso para evitar o excesso de mimos no colo das mães e empregadas. Nesse mesmo sentido, era recomendado o uso do berço e não pegar no colo os bebês toda vez que chorassem (Freire, 2006).

Este artigo está dividido em cinco partes, nas quais são discutidas, após a apresentação da metodologia do trabalho, as principais controvérsias estabelecidas entre os modos sensíveis de criação infantil e a "maternidade científica”, no que diz respeito à natureza do choro infantil. Subjacente às críticas de deixar o bebê chorando no berço até dormir, encontra-se um modelo médico explicativo baseado na noção de apego, que, no estilo de cuidados com crianças analisado, promove o estabelecimento de um contato corporal contínuo entre mãe e filho e remete a um retorno ao "natural" e ao "tradicional". Posteriormente, essa ideia é problematizada, evidenciando que os modos sensíveis de criação infantil se aproximam de certos valores ocidentais modernos. Nas considerações finais, aponta-se quais aspectos desse estilo de cuidados com crianças se distanciam dos discursos do movimento higienista e da "maternidade científica". Por fim, conclui-se que os modos sensíveis de criação infantil constituem uma inflexão contemporânea desse processo de medicalização dos cuidados com crianças.

\section{Metodologia: reflexões a partir da etnografia}

A discussão apresentada neste trabalho se fundamenta na pesquisa antropológica realizada entre 2013 e 2016, período no qual participamos de ambientes e experiências diversificados na cidade de Porto Alegre/RS, vinculados aos modos sensíveis de criação infantil, tais como grupos em redes sociais, bazares, marcha pela humanização do parto, audiências públicas sobre humanização da assistência ao parto, entre outros. Além disso, grande parte da pesquisa de campo etnográfica foi realizada em quatro espaços, a saber:

1. O "Nascer Sorrindo", que é um grupo de apoio presencial a gestantes e "casais grávidos"4 que pretendem ter um "parto ativo", 5 entretanto os temas abordados nos encontros mensais não se limitaram ao parto, incluíram também temas como amamentação, introdução alimentar, vacinas e criação infantil. A coordenação do grupo estava a cargo de uma doula ${ }^{6}$ e instrutora de ioga para gestantes e mães com bebês e de uma militante do "parto ativo" que se tornaram atuantes nesse campo após a experiência de parto de seus filhos. Durante os encontros, as participantes relatavam suas vivências sobre parto, amamentação, puerpério e criação infantil. Algumas vezes, os encontros contavam também com pessoas convidadas para tratar de temas específicos.

2. O ciclo de três palestras "O estilo de vida contemporâneo e sua influência na saúde da criança”, promovido por um grupo de pais e educadores que queriam criar uma escola orientada pela pedagogia Waldorf. ${ }^{7}$

4 De acordo com Tania Salem (2007), o fenômeno “casal grávido” se caracteriza tanto pelo envolvimento dos cônjuges no pré-natal e no parto como pela busca de um "parto natural”, de modo a limitar o uso de tecnologias introduzidas pela obstetrícia moderna às situações em que se fazem necessárias.

5 Conceito criado por Janet Balaskas (2008) que aponta para a participação ativa da mulher no parto, tendo a fisiologia do parto e suas escolhas respeitadas pela equipe de profissionais que a assistem.

6 A palavra doula tem origem na Antiga Grécia e significa "mulher que serve". Atualmente, nomeia as mulheres que dão suporte físico e emocional a outras mulheres antes, durante e após o parto.

7 Elaborada por Rudolf Steiner (1861-1925) com base na antroposofia. Fundamenta-se na compreensão do ser humano como um ente físico, 
3. O "Curso Básico de Prática Pedagógica Waldorf”, organizado por uma euritmista, ${ }^{8}$ com formação em pedagogia Waldorf. 0 curso envolveu atividades teóricas e principalmente práticas, algumas das quais foram coordenadas por pessoas convidadas que tinham algum tipo de vínculo com essa pedagogia: uma médica pediatra com formação antroposófica, um educador Waldorf, uma "mãe Waldorf”9 que realizava trabalhos manuais com feltro e uma "mãe Waldorf" que trabalhava com jogos de improvisação e psicodrama.

4. O "Espaço de Integração Timbaúva", onde transcorriam as Tardes no Verde, atividade na qual crianças de idades variadas desempenhavam tarefas lúdicas em meio à mata, árvores, insetos e córregos.

Nesses espaços, realizou-se observação participante, processo de pesquisa que implica no convívio prolongado do pesquisador junto a um grupo de pessoas, a fim de observar uma problemática previamente definida. Tal observação inclui diferentes elementos, como o ambiente, o comportamento das pessoas, a linguagem verbal e não verbal, os relacionamentos entre os informantes e destes com o pesquisador, bem como a temporalidade dos eventos (Víctora; Knauth; Hassen, 2000). Os acontecimentos vivenciados foram registrados de maneira minuciosa em um diário de campo ao longo da pesquisa empírica. Cabe salientar, contudo, que este artigo apresenta uma reflexão baseada nos dados coletados durante o trabalho de campo, entretanto, não é em si um artigo de caráter etnográfico.

\section{Deixar ou não chorar? Controvérsias em torno do choro infantil}

Controvérsias em torno do choro infantil emergiram em uma discussão no grupo Nascer
Sorrindo na rede social Facebook, quando uma participante postou uma matéria sobre o método do neurologista e pediatra espanhol Eduard Estivill (Estivill; Béjar, 2004) para ensinar a criança a dormir à noite toda. Conforme o método, no primeiro dia, recomenda-se aguardar que a criança chore durante um minuto antes de entrar no quarto e permanecer a certa distância do berço, apenas para mostrar que não está sozinha. Nos dias seguintes, esse tempo de espera vai aumentando para dois, três, quatro minutos, e assim sucessivamente até que a criança aprenda a dormir sozinha. Na discussão do grupo, o foco das críticas recaiu fundamentalmente sobre a atitude dos pais frente ao choro da criança. ${ }^{10}$

Algumas participantes referiram terem recorrido (mesmo que em parte) ao método com sucesso, e defenderam a necessidade de estabelecer rotinas e de ensinar a criança a dormir sozinha se isso não ocorresse de maneira espontânea. Outras participantes consideraram o ato de deixar a criança chorar um método atrasado, que, embora pudesse ser efetivo, pois a criança poderia até mesmo parar de chorar e dormir, isso ocorreria por ela ter aprendido que não adianta chorar, porque está desamparada e ninguém virá por ela. 0 sentimento de desamparo que decorreria do não acolhimento das necessidades da criança teria consequências negativas, tais como ansiedade e insônia quando adulta. Em contrapartida, a prática do coleito possibilitaria às crianças tornarem-se, com o tempo, mais seguras, confiantes e independentes. Como considerado por uma das participantes: acho que se as crianças dormem com os pais se tornam mais seguras. Querer que um bebê de 7 meses durma a noite toda? Acho triste essa independização precoce que a nossa sociedade impõe nas crianças (Ana).

Este dado do trabalho de campo vai muito além de uma disputa por preferências exposta nas

anímico e espiritual, e busca possibilitar o desenvolvimento em sua totalidade, cultivando o pensar, o sentir e o querer da criança. Para um aprofundamento sobre a antroposofia e a pedagogia Waldorf, recomenda-se o site da Sociedade Antroposófica do Brasil. Disponível em: <https://bit.ly/2QJ51Ba>.

8 Euritmia é uma prática corporal baseada na antroposofia que tem por objetivo harmonizar corpo, alma e espírito.

9 Expressão utilizada frequentemente nesse campo de práticas para nomear as mulheres cujos filhos frequentam um jardim de infância ou uma escola que segue essa pedagogia.

10 Ao longo do trabalho de campo, identificou-se uma grande variação de formas de praticar o coleito: a noite toda ou parcialmente, somente nos primeiros meses ou durante anos, na mesma cama ou em leitos separados, mas no mesmo quarto. Algumas famílias nem mesmo o praticavam. Contudo, uma maior concordância era alcançada nas críticas à prática de deixar o bebê chorando no berço até dormir. 
redes sociais, quando se leva em consideração que subjacente a essas controvérsias em torno do choro infantil e, consequentemente, da resposta tida como adequada para tal comportamento, há uma tensão entre modelos médicos explicativos acerca da natureza do choro infantil. É possível encontrar em destacados manuais de puericultura do século XX, recomendações para não dar colo à criança de modo frequente. Tais orientações têm como pressuposto que o choro é um "truque" da criança para manter seus “privilégios” (Spock, 196o, p. 145):

Se a mãe é muito solícita e pega o bebê no colo, carregando-o toda a vez que chore, verificará ao termo de alguns meses, que passará a levantar os braços como pedindo para ser carregado, sempre que estiver acordado. Se continuar a ceder, ele concluirá, em pouco tempo, que tem a sua pobre mãe sob seu controle e passa a exigir seu serviço sob forma ainda mais desagradável e tirânica.

Essa formulação da criança como tendo sentimentos egoístas e atitudes tiranas, que faz uso do choro como um estratagema para dominar seus pais, conflita com outra versão na qual o choro é um comportamento "natural" e sem malícia da criança. Essa última versão foi possibilitada pela noção de apego, que tem origem na teoria de Bowlby. Recorrendo a experimentos realizados com animais, Bowlby questionou a teoria de Freud, a qual considerava que a ligação do bebê com sua mãe advinha do fato do bebê ter necessidades orgânicas de alimento e conforto (que constituiriam seu impulso primário) e dele aprender que sua mãe é quem satisfaz suas necessidades orgânicas. Contrariamente a Freud, Bowlby argumentou que o vínculo da criança com a figura materna resultava da atividade biológica do "sistema comportamental de apego”, característico da espécie, não sendo o choro, portanto, um comportamento aprendido. Nesse processo, a alimentação teria um papel secundário. Chorar, balbuciar, sorrir, levantar os braços, agarrar-se, assim como a locomoção e a sucção não nutritiva são apontadas como parte do repertório do comportamento de apego, o qual tem a proximidade como resultado previsível (Bowlby, 2002).

Contudo, em seus trabalhos, Bowlby fala em "proximidade" entre o bebê e a figura materna sem definir o estabelecimento de contato corporal contínuo entre eles como forma de cuidado adequada à espécie humana. Essa formulação do apego é mais bem operada nos discursos sobre os modos sensíveis de criação infantil, por meio de argumentos cientificistas. Uma dessas alegações baseia-se na comparação com o comportamento animal, especialmente o de primatas. Entre outras espécies, como a dos coelhos, que deixam suas crias sozinhas em tocas para procurar alimentos, os filhotes não choram nem se movem até sua mãe retornar; enquanto entre os primatas, que costumam carregar consigo os filhotes, quando estes são deixados sozinhos, sua reação é chorar. A observação do comportamento primata evidenciaria que o ambiente "natural" dos seres humanos nos primeiros meses de vida é o colo, especialmente, de sua mãe (González, 2015).

Outro argumento que aponta no mesmo sentido é conhecido como teoria da exterogestação. Tal teoria parte do pressuposto de que, durante a evolução humana, os homo sapiens adquiriram inteligência e, consequentemente, um cérebro com dimensões maiores. Em decorrência disso, os seres humanos nasceriam mais cedo que os outros mamíferos, caso contrário a criança não passaria pela pélvis da mãe no momento do parto. Por nascerem imaturos, antes que seu sistema nervoso central estivesse completamente amadurecido, os seres humanos demorariam então mais tempo para andar em comparação às demais espécies de animais, sendo extremamente dependentes de cuidados (González, 2015). Propõe-se então uma espécie de "gestação fora do útero" por mais nove meses, o que implica em dormir junto ao bebê, amamentá-lo em livre demanda e carregá-lo junto ao se deslocar.

Embora as práticas de apego remetam a uma profunda dependência física e emocional, identificou-se durante o trabalho de campo que o desenvolvimento da autonomia da criança é um elemento de suma relevância para os adeptos 
dos modos sensíveis de criação infantil, ${ }^{11}$ o que à primeira vista parecia paradoxal. Contrariamente à ideia de que é possível ensinar as crianças a serem independentes por meio de treinamento ou disciplinamento como proposto pelo método Estivill, os modos sensíveis de criação infantil se pautam na concepção de independência e autonomia como decorrentes de um processo de amadurecimento biológico. Ou seja, a autonomia é tomada como uma potencialidade natural do indivíduo, que "sempre esteve presente", mas precisa de tempo e preparo para emergir.

Nesse sentido, o desenvolvimento é compreendido como um processo que não é linear, mas sim composto por sucessivos estágios. Cada estágio apresenta uma lógica que é abarcada por um estágio posterior no qual uma outra lógica opera, constituindo-se como uma mudança radical. Um estágio prepara para o próximo e, portanto, nenhum pode ser pulado nesse caminho do desenvolvimento. Assim, vistos de uma perspectiva sincrônica, pode-se pensar que os discursos e práticas sobre os modos sensíveis de criação infantil incitam uma relação de dependência física e afetiva, a qual se entende corresponder às necessidades de vínculo e afeto das crianças nos primeiros anos de vida. Contudo, espera-se que a partir dessa relação que a criança estabelece (especialmente com a figura materna), em um segundo momento, ela se torne confiante, sentindo-se segura para brincar e agir com uma maior independência.

\section{Modos sensiveis de criação infantil: retorno ao natural?}

Uma primeira questão trazida tanto pelos modos sensíveis de criação infantil como pelas prescrições mais alinhadas à "maternidade científica" e que precisa ser relativizada é a noção de desenvolvimento infantil tendo em seu horizonte a independência individual. Cabe salientar que a autonomia se torna relevante em uma configuração de valores particular, própria da "sociedade ocidental moderna": o individualismo (Dumont, 1985). Em seu trabalho etnográfico realizado junto aos Xikrin, grupo indígena Kayapó que vive no sudoeste do Pará, Clarice Cohn (200o) nos mostra um processo que não segue essa mesma lógica, partindo de um primeiro momento de maior autonomia da criança para outro de obediência aos costumes do grupo. Entre os Xikrin não se espera que até certa idade as crianças conheçam e, portanto, sigam as regras da vida social que quando adultas serão obrigadas a respeitar. Isso permite a elas vivenciarem uma liberdade em relação às normas que não terão oportunidade de experimentarem novamente quando crescerem. Exemplo disto é a atuação das crianças como mensageiras entre as casas por não terem ainda seus movimentos impedidos pela distância social, que pauta as relações de evitação entre os adultos e que restringe a interação entre determinadas categorias de pessoas.

Um segundo aspecto diz respeito à ideia de um retorno ao natural mediante o resgate de práticas de cuidado tradicionais pelos modos sensíveis de criação infantil. Ainda que algumas dessas práticas sejam desempenhadas nas chamadas "sociedades tradicionais”, ao se vincular à noção de apego elas adquirem sentidos particulares que não podem ser universalizados a outros contextos nos quais essas práticas são realizadas. Trabalhos etnográficos como os de Alma Gottlieb (2013) e de Clarice Cohn (2000) permitem observar que, embora a amamentação seja desempenhada pelos dois grupos sociais estudados pelas autoras, tal prática se associa a concepções de corpo, e de vida e morte, sobre o choro infantil, os sentimentos e as necessidades da criança, que são específicas de cada grupo, o que confere à amamentação um sentido particular.

Os Xikrin, por exemplo, têm grande preocupação com que as crianças não chorem e, para que isso não ocorra, evitam bater-lhes ou fazer com que se zanguem. Quando uma criança de colo chora, os adultos buscam distraí-la, consolá-la ou então levá-la até a mãe para que lhe dê o peito. Todo esse cuidado para que as crianças não chorem se deve ao perigo do karon (frequentemente traduzido por alma) ficar bravo, ir embora e não voltar mais, levando à morte da criança. Embora o karon possa durante toda a vida

11 Como promover a autonomia das crianças foi um dos temas discutido durante os encontros do grupo de estudos dos educadores das Tardes no Verde. 
sair e voltar ao corpo durante os sonhos, as crianças pequenas estão em uma situação mais vulnerável, pois suas peles ainda são "moles", sendo pouco capazes de guardar o karon enquanto seu corpo ainda não tenha "endurecido".

Em sua pesquisa acerca dos cuidados com bebês entre os Beng, grupo que habita a região de Côte d'Ivoire, no oeste africano, Gottlieb (2013) refere que, para esse coletivo, quando uma pessoa morre, ela permanece por um longo período em um lugar próspero denominado wrugbe (cidade dos espíritos) até reencarnar. Nos primeiros tempos após o nascimento, as memórias da estadia no wrugbe são muito vívidas e os bebês sentem saudades, podendo ser atraídos a retornarem. 0 choro assim como o estado de constipação e de enfermidade são formas de os bebês comunicarem seus desejos de terem novamente algo que perderam ao sair do wrugbe. Os pais se esforçam para tornar esta nova vida atraente e confortável para seus filhos. A amamentação é uma forma de persuadi-los a ficar, mostrando-lhes quanto esta vida pode ser prazerosa e abundante tanto no que se refere ao sustento alimentar como afetivo. Assim, se uma criança começa a chorar, qualquer mulher que estiver próxima pode dar-lhe o peito, mesmo aquelas que não estiverem amamentando. Os pais costumam consultar com adivinhos capazes de entender a língua dos bebês, a fim de atender a seus desejos, o que frequentemente se relaciona com enfeitar-lhes o corpo com os adornos que costumavam usar no wrugbe.

Além disso, observou-se durante o trabalho de campo (na participação dos encontros do grupo de apoio, nos cursos e nos bazares) que, apesar de os modos sensíveis de criação infantil evocarem um retorno ao natural, a prática da amamentação, bem como outras práticas que constituem esse estilo de cuidados com crianças, envolveu uma intensa preparação dos casais (principalmente das mulheres), mediante a participação em grupos de apoio, palestras, cursos, grupos de discussão em redes sociais, e a aquisição de todo um conjunto de objetos e serviços, como livros, slings, doulas, consultoras em amamentação, entre outros. Isso evidencia a amamentação não como um ato unicamente natural ou biológico, mas um uso que as mulheres podem fazer de seus corpos, que requer uma educação corporal. Essa aprendizagem dos modos sensíveis de criação infantil promovida pelos grupos de apoio a mulheres e casais grávidos aparece claramente na entrevista de Clarissa, 34 anos, proprietária do Espaço Timbaúva:

muita coisa que falavam ali, eu nunca ia saber disso, não ia ter como eu descobrir sozinha. Claro, eu lia muita coisa, eu comecei a ler e minhas leituras eram só sobre parto, mas o grupo Nascer Sorrindo, olha foi fundamental para eu me sentir segura para maternar, para amamentar, para parir, para tudo. Vendo aquele monte de mulher falando daquilo, dando relatos, experiências.

Ainda que associado à ideia de um retorno ao natural e às práticas de cuidado tradicionais, os discursos sobre os modos sensíveis de criação infantil não prescindem de argumentos que evocam a ciência, à semelhança da "maternidade científica", mesmo que incorporem um conjunto de conceitos e modelos médicos diferentes e refutem o caráter normativo de suas orientações. Essas são frequentemente apresentadas como "sugestões", "princípios", ou ainda a forma mais adequada de cuidar das crianças (embora isso pareça suficientemente categórico), cabendo ao leitor fazer suas escolhas, seguir sua “intuição". Essa questão emerge na fala de Alessandra, uma das coordenadoras do Grupo Nascer Sorrindo, quando questionada se ela fazia criação com apego. Ela defende que cada pessoa, cada família crie:

a sua maneira de fazer o melhor da criação com apego, a sua criação com apego. Tudo isso pra mim são caminhos, mas a gente vai ver outras tantas pessoas que fizeram outros caminhos efoi tão bom quanto. E são apegáveis, são carinhosos, são acolhedores das crianças. Talvez melhor que se tivesse feito aquilo [que estava escrito] porque tem a ver com que cada criança demanda. É muito mais legal pra criança, aceitar os seus limites do que tentar trabalhar num livrinho, numa cartilha, e filho não é cartilha, não tem regras, não tem regras prontas...

Contudo, cabe salientar, ainda que brevemente, que embora sensibilidades, sentimentos e intuições sejam frequentemente vistos como menos sujeitos ao controle 
externo do que pensamentos, estes são também tributários de um contexto social e histórico (Rezende; Coelho, 2010). E que, como aponta Foucault (1979, p. 8), o poder (implicado em toda forma de saber) se sustenta não por sua força repressiva e coercitiva, mas por sua característica positiva e produtiva, capaz de engendrar práticas e sensibilidades.

\section{Considerações finais}

Ao longo deste artigo problematizamos a ideia de que práticas de cuidado com crianças que colocam em evidência os sentidos do corpo e exaltam os afetos, as emoções, a intuição e a empatia constituam um retorno ao natural. Nesse sentido, sugerimos que os modos sensíveis de criação infantil estão mais próximos de certos valores ocidentais modernos e do fenômeno de medicalização das práticas cotidianas de cuidado com crianças do que os discursos que operam nesse campo de práticas podem levar a crer. A associação de práticas como a amamentação, o coleito e o ato de carregar a criança junto ao corpo com a ideia de um retorno ao natural, de algum modo, recupera o discurso médico até o início do século XX que buscava persuadir as mulheres a não contrariarem as leis da natureza e seguirem o exemplo dos animais (mamíferos).

Mas se os modos sensíveis de criação infantil estão assim tão próximos do fenômeno de medicalização das práticas cotidianas de cuidado com crianças, em que medida esse estilo de cuidados se distancia dos discursos do movimento higienista e da "maternidade científica", conferindo-lhe um caráter particular? Dentre os aspectos que caracterizam os modos sensíveis de criação infantil, três em especial os diferenciam. Um, diz respeito ao fato de buscarem a afirmação do indivíduo (autônomo e livre), ao mesmo tempo que enfatizam a totalidade, o englobamento do ser humano por uma dimensão maior, de modo a constituir uma unidade, seja com o universo, a natureza ou a coletividade humana. Esse aspecto está presente no caráter totalizante da noção de apego e das práticas investigadas, que entrelaçam a criança ao corpo da mãe e, de maneira mais ampla, ao ambiente que a circunda. Um segundo aspecto remete ao desejo de um retorno ao natural e a essa unidade que teria sido perdida, enquanto contraponto aos males da cultura e da civilização. Diferentemente dos discursos vigentes até o início do século XX que procuravam naturalizar a maternidade, o caráter natural conferido às práticas de criação investigadas neste trabalho se reveste de um sentido contracultural, de modo a acirrar as oposições indivíduo/sociedade e natureza/cultura. Sociedade e cultura, neste campo de discursos e práticas, dizem respeito a diferentes elementos característicos da modernidade ocidental que se configuram como males.

A partir do trabalho de Isabel Carvalho (2001), pode-se dizer que os modos sensíveis de criação infantil são tributários de um movimento de longa duração que surgiu no final do século XVIII, e que, ao longo do tempo, volta a emergir em determinados contextos: o Romantismo. A ideia de um ser humano que nasce bom (incapaz de ter sentimentos egoístas e atitudes tiranas) e que a sociedade o corrompe tem justamente o Romantismo como pressuposto subjacente. Entre as características constitutivas do Romantismo, Duarte $(2004,2012)$ ressalta a ênfase: na totalidade, mas que também pode deslocar-se para a ideia de singularidade ao tomar uma unidade como totalidade em si; na diferença, em oposição à igualdade; no fluxo temporal dos fenômenos; na pulsão como uma disposição interior própria dos seres vivos; na sensibilidade; na subjetividade; na criatividade; na espontaneidade; e na experiência.

Um terceiro aspecto característico dos modos sensíveis de criação infantil é o princípio da psicologicidade, ligado à percepção do ser humano como ser psicológico e à psicologização da retórica, que chama a atenção para uma dimensão subjetiva e individual dos sujeitos e promove o exame constante das emoções (Salem, 2007). Nesse sentido, as práticas de criação infantil investigadas se inserem em um processo mais amplo de difusão de uma cultura psicanalítica entre as camadas médias urbanas, ocorrido a partir da década de 1980 no país (Figueira, 1985). As relações entre os fenômenos da medicalização e da psicologização são complexas e, embora haja tensionamentos entre ambos (explícitos nas críticas à medicalização presentes nos discursos dos modos sensíveis de criação infantil), ocorrem também situações em que esses dois registros se combinam. Alguns trabalhos etnográficos apontam para um processo de psicologização nos discursos e 
práticas médicas em diferentes campos de atuação profissional, como é o caso, por exemplo, dos cuidados paliativos (Menezes, 2004), de grupos de gestante (Rezende, 2012), do parto natural (Salem, 2007) e da medicina de família (Bonet, 2014).

Esse também é o caso da noção de apego, a qual diz respeito a uma dimensão que é tanto psicológica como fisiológica, tanto individual como universal. Isso porque o apego assinala os laços afetivos nos primeiros anos de vida como condição para o desenvolvimento normal dos seres humanos, que marcaria de maneira indelével as experiências sentimentais, os relacionamentos interpessoais e as características individuais. Mas também remete a um sistema comportamental, um mecanismo biológico e, portanto, universal da espécie humana. Poder-se-ia dizer que ocorre uma "corporificação do psicológico", recorrendo à expressão utilizada por Jane Russo (1993) para elucidar a noção de continuidade entre corpo e mente vigente entre as terapias corporais. Como refere a autora, nas terapias psicológicas que se designam como corporais, as fronteiras entre medicina e psicologia, entre corpo e mente deixam de orientar o trabalho terapêutico, uma vez que é pelo corpo que se acessa a mente.

Ainda, nos espaços etnografados, identificou-se que não apenas médicos e psicólogos desempenhavam o papel de autoridade, mas que também os casais, especialmente as mulheres que haviam passado pela experiência do parto natural e de cuidados com os filhos, muitas vezes exerciam de algum modo esse papel. Algumas mulheres foram convidadas a relatarem suas experiências ou a coordenar alguma atividade pontual. Outras participaram de cursos de formação e passaram a atuar como doulas, consultoras de amamentação ou de sling. Desta maneira, embora psicólogos e médicos nem sempre estivessem no momento, um discurso tanto psicologizante como medicalizante era compartilhado pelos presentes (autoridades e participantes) nas mais distintas atividades.

Frente ao exposto, pode-se concluir que os modos sensíveis de criação infantil, mais do que representarem um retorno ao "natural" e ao "tradicional" ou uma pretensa desmedicalização, constituem uma inflexão contemporânea do processo de medicalização dos cuidados com crianças. Embora, como afirma Peter Conrad (1992), a medicalização seja uma via de mão dupla, esse não é o caso dos discursos e práticas analisados neste artigo, os quais incitam mães e pais a buscarem informações, seguirem sua intuição e tomarem decisões conscientes, o que implica na incorporação de termos e modelos médicos. 0 que ocorre de fato é um adensamento desse processo de medicalização das práticas de criação infantil com a inclusão de termos e modelos provenientes do campo da biologia e da psicologia, como é o caso da noção de apego. Pois se tópicos como o choro e o sono infantil, o contato corporal com o bebê e a amamentação passaram a ser tratados como problemas médicos entre o século XVIII e XIX, conflitando com modelos explicativos leigos, com a emergência dos modos sensíveis de criação infantil, um novo tensionamento se produz, agora, entre dois diferentes modelos médicos. Com isso, não estamos sugerindo que os modos sensíveis de criação infantil estão (ou irão) substituir outras formas de cuidado mais próximas da "maternidade científica". Nossa intenção neste artigo foi chamar a atenção para o aspecto heterogêneo e multidirecional do fenômeno da medicalização infantil, do qual a emergência de novas sensibilidades representa um desdobramento.

\section{Referências}

APPLE, R. D. Mothers and medicine: a social history of infant feeding, 1890-1950. London: The University of Wisconsin Press, 1987.

BALASKAS, J. Parto ativo: guia prático para o parto natural. 2. ed. São Paulo: Ground, 2008.

BONET, O. Os médicos da pessoa: um olhar antropológico sobre a medicina de família no Brasil e na Argentina. Rio de Janeiro: 7 Letras, 2014.

BOWLBY, J. Apego e perda: apego: a natureza do vínculo. 3. ed. São Paulo: Martins Fontes, 2002. v. 1.

CARVALHO, I. C. M. A invenção do sujeito ecológico: sentidos e trajetórias em educação ambiental. 2001. Tese (Doutorado em Educação) Universidade Federal do Rio Grande do Sul, Porto Alegre, 2001.

COHN, C. A criança indígena: a concepção

Xikrin de infância e aprendizado. 2000. 
Dissertação (Mestrado em Antropologia Social) Universidade de São Paulo, São Paulo, 2000.

CONRAD, P. Medicalization and social control. Annual Review of Sociology, Palo Alto, v. 18, p. 209-232, 1992.

COSTA, J. F. Ordem médica e norma familiar. Rio de Janeiro: Graal, 2004.

DONZELOT, J. A polícia das famílias. Rio de Janeiro: Graal, 1980.

DUARTE, L. F. D. A pulsão romântica e as ciências humanas no ocidente. Revista Brasileira de Ciências Sociais, São Paulo, v. 19, n. 55, p. 5-18, 2004.

DUARTE, L. F. D. O paradoxo de Bergson: diferença e holismo na antropologia do ocidente. Mana, Rio de Janeiro, v. 18, n. 3, p. 417-448, 2012.

DUMONT, L. O individualismo: uma perspectiva antropológica da ideologia moderna. Rio de Janeiro: Rocco, 1985.

ESTIVILL, E.; BÉJAR, S. Nana, nenê: como resolver o problema de insônia do seu filho. São Paulo: Martins Fortes, 2004.

FIGUEIRA, S. A. (Org.). Cultura da psicanálise. São Paulo: Brasiliense, 1985.

FOUCAULT, M. Microfísica do poder. Rio de Janeiro: Graal, 1979.

FREIRE, M. M. L. Mulheres, mães e médicos: discurso maternalista em revistas femininas (Rio de Janeiro e São Paulo, década de 1920). 2006. Tese (Doutorado em História das Ciências e da Saúde) Fundação Oswaldo Cruz, Rio de Janeiro, 2006.

FREIRE, M. M. L. 'Ser mãe é uma ciência': mulheres, médicos e a construção da maternidade científica na década de 1920. História, Ciências, Saúde-Manguinhos, Rio de Janeiro, v. 15, p. 153-171, 2008. Suplemento 1.

GONZÁLEZ, C. Bésame mucho: como criar seus filhos com amor. São Paulo: Timo, 2015.

GOTTLIEB, A. Tudo começa na outra vida: a cultura dos recém-nascidos no oeste da África. São Paulo: Editora Fap-Unifesp, 2013.

MENEZES, R. A. Em busca da boa morte: antropologia dos cuidados paliativos. Rio de Janeiro: Garamond, 2004.

RAPLEY, G.; MURKETT, T. El niño ya come solo: consiga que su bebé disfrute de la buena comida. Barcelona: Medici, 2012.

REZENDE, C. B. Emoção, corpo e moral em grupos de gestante. Revista Brasileira de Sociologia da Emoção, João Pessoa, v. 11, n. 33, p. 830-849, 2012.

REZENDE, C. B.; COELHO, M. C. P. Antropologia das emoções. Rio de Janeiro: FGV, 2010.

RUSSO, J. O corpo contra a palavra: as terapias corporais no campo psicológico dos anos 80 . Rio de Janeira: UFRJ, 1993.

SALEM, T. O casal grávido: disposições e dilemas da parceria igualitária. Rio de Janeiro: FGV, 2007.

SPOCK, B. Meu filho, meu tesouro: como criar seus filhos com bom senso e carinho. Rio de Janeiro: Record, 1960.

VÍCTORA, C. G.; KNAUTH, D. R.; HASSEN, M. N. A. Pesquisa qualitativa em saúde: uma introdução ao tema. Porto Alegre: Tomo, 2000.

\section{Contribuição dos autores}

Hernandez analisou e interpretou os dados e redigiu o artigo. Ambas as autoras conceberam o projeto, realizaram a revisão crítica relevante do conteúdo intelectual e aprovaram a versão final.

Recebido: 22/07/2020

Aprovado: $25 / 08 / 2020$ 